\title{
The behaviour of grower pigs in relation to housing systems
}

\author{
W. A. Ruiterkamp (Department of Animal Husbandry, Veterinary Faculty, P.O. \\ Box 80.156, 3508 TD Utrecht, Netherlands)
}

Received 3 January 1986; accepted 17 October 1986

\begin{abstract}
Two slatted floor systems and the Danish system are compared to better understand how grower pigs function in modern, intensive housing systems. Based on production results, data about culled animals and particularly behavioural data, it is concluded that the well-being of grower pigs is more impaired in both slatted floor systems than in the D system.

Key words: grower pigs, housing systems, production, culling, behaviour, wellbeing, ontogeny.

Introduction. Developments in swine husbandry during the past 25 years have led to an intensive, mechanized and rational way of animal husbandry (e.g. large production units, high stocking rates, slatted floor systems without litter). These developments have raised questions concerning farm animal well-being. The objective of this study is an inventorial and comparative investigation into the way grower pigs function in modern housing systems.
\end{abstract}

Literature. It appears that different scientific disciplines may contribute to a better insight into the relation between animals and their environment. These disciplines are animal husbandry (production), veterinary science (morbidity, mortality, external injuries), physiology (hormonal and immunological parameters related to stress), and ethology (behaviour) (Dawkins, 1980; van Putten, 1982).

The relation between the animal and its environment is affected by a continuous interaction. This is probably regulated by a biological control system (Baerends, 1976). Based on this model, that is used in this study, impaired well-being is a (conflict) situation in which animals do not dispose of suitable (behavioural) actions that decrease and finally dissolve the discrepancy between the actual value and a (genetic, ontogenetic or learned) setpoint of environmental features (Wiepkema, 1983).

Material and methods. The pigs were mainly Dutch Landrace and Great Yorkshire purebreds and crossbreds, both females and castrated males. One half of the pigs were born and reared in half and fully slatted floor pens respectively (slat-pigs), and the other half were born and reared in pens provided with straw (straw-pigs). After rearing, both slat-pigs and straw-pigs were housed in three different systems that were installed in one fattening house. Two of these were modern, slatted floor systems (without straw), either fully slatted (FS, $0.65 \mathrm{~m}^{2}$ per pig) or half slatted (HS, $0.74 \mathrm{~m}^{2}$ per pig). The reference system was the more traditional Danish sys- 
tem (D, $0.92 \mathrm{~m}^{2}$ per pig) with straw. Each system included 16 pens of 10 grower pigs each. Five fattening rounds were completed and in total 2400 pigs were involved in the study.

The investigations concerned production, culling of animals and especially behaviour. Group observations on behaviour were made during five separate 24-hour periods per fattening round. During such a 24-hour period (eight three-hour periods) the number of pigs in each pen performing each of nine behaviour elements was recorded 40 times. Behavioural observations of individual pigs took place during the third fattening round. Both in the FS and the D system 12 animals were observed individually 6 times during a 20-minute period, and the sequence of 24 behaviour elements (either performed or received) was recorded. The data of production traits and group observations on behaviour were analysed with an F-test (analysis of variance), a t-test or a $\chi^{2}$-test. By means of the individual observations on behaviour the structure of the behaviour pattern was analysed with a frequency analysis, a single-linkage cluster analysis and a sequence analysis.

\section{Results}

Production and culling. Growth rate and feed intake in both slatted floor systems were $50 \mathrm{~g} /$ day and $200 \mathrm{~g} /$ day respectively lower than in the D system. The feed conversion was about the same in the three systems. The percentage of carcasses in the two highest quality classes (EAA $+1 \mathrm{~A}$ ) was about 12 and 5 higher for the FS and the HS system respectively as compared with the D system. From a total of 2400 pigs, $202(8.4 \%)$ were culled because of veterinary or zootechnical reasons. The culling percentages for the FS, HS and D system were $14.2,8.1$ and 2.9 respectively. The differences between the number of culled animals per housing system were significant. The major reasons for culling were poor growth rate $(31 \%)$, cannibalism (victims, $29 \%$ ) and locomotion disorders (13\%).

Behaviour. Based on the cluster analysis of the individual observations and functional relationships 5 sets of behavioural elements can be distinguished: (1) behaviour associated with eating and drinking, (2) the 'non-active' set, (3) behaviour directed at penmates, (4) behaviour directed at physical objects, and (5) the compound element straw acts. The frequency and sequence analysis show that straw acts played an important role in the behaviour repertoire in the D system. The pigs in the FS system showed very frequently object- and penmate-directed behaviour, most likely as alternatives for straw acts. However, there are several indications and arguments that these two sets of behaviour elements did not yield feedback information corresponding to that of straw acts. In terms of the control system model this is a conflict situation that cannot be resolved by the pigs with their behaviour repertoire. Next to this, penmate-directed behaviour causes a disturbance of lying behaviour, may lead to (badly) wounded ears and tails (cannibalism), and has a negative influence on social relations, especially in the FS system (leading to less feed intake and poorer production). During 'non-active' phases in behaviour (after lying down) the pigs in the FS system received very often penmate-directed behaviour elements, and they also exhibited more pronounced and more frequently abnormal elements, such as sham chewing and motionless sitting. Sham chewing is a kind of 
stereotypy, and in this way the animal performs self-stimulation. Besides, recent research (Cronin, 1985) indicates that endogenous opioids (endorphins) are presumably involved in stereotypies. During motionless sitting a pig does not exhibit interest in the external environment and it is likely a kind of apathy. Both elements enable pigs to isolate themselves non-physically from an insufficient environment (auto-isolation).

The group observations on behaviour showed a great and significant influence of the three actual housing systems on the frequencies of six elements (rooting at penmates, nibbling at penmates, tail biting, massaging, sitting and chewing acts), and a relatively high frequency of straw acts in the D system. The highest frequencies of the six elements were observed in the FS system and the lowest ones in the D system, while the HS system was in an intermediate position. However, the differences between the FS and the HS system were smaller than those between the HS and the D system. Housing during the farrowing and rearing period had also a significant influence on the behaviour frequencies of grower pigs, but the magnitude of this influence was probably smaller than that of the actual system during the fattening period. For example, the frequency of straw acts of the slat-pigs was much higher than that of the straw-pigs in the D system, and this difference was rather constant throughout the fattening period. This ontogenetic effect also indicates that explorative, substrate-directed behaviour is an important element in the behaviour repertoire of pigs. Furthermore, this early experience effect on behaviour at an elder age is dependent on the behaviour element. Some elements are relatively more affected by the actual housing system (rooting at penmates, nibbling at penmates, tail biting), and other ones are more modified by early experience (sitting, chewing acts, massaging).

Discussion and conclusions. The ethological results demonstrate a dual behaviour strategy of the pigs towards intensive slatted-floor housing systems that is influenced by early experience. On the one hand, the behaviour directed at the environ ment (object and penmate) indicates a conflict situation with regard to an insufficient physical environment. On the other hand, the animals presumably attempt to reduce or cut off the interaction with the external environment in order to mask (temporarily) this conflict. These two phases probably alternate in the behaviour repertoire. Together with the production results and the data on culling, this indicates that grower pigs have more difficulties in adapting to both slatted-floor systems compared to the D system, and this is obviously a matter of reduced wellbeing.

\section{References}

Baerends, G. P., 1976. The functional organization of behaviour. Animal Behaviour 24: 726-738.

Cronin, G. M., 1985. The development and significance of abnormal stereotyped behaviours in tethered sows. Thesis, Agricultural University, Wageningen.

Dawkins, M. S., 1980. Animal suffering. The science of animal welfare. Chapman and Hall, London.

Putten, G. van, 1982. Zum Messen von Wohlbefinden bei Nutztieren. In: D. W. Fölsch \& A. Nabholz 


\section{W. A. RUITERKAMP}

(Hrsg.), Ethologische Aussagen zur artgerechten Nutztierhaltung, p. 78-95. Birkhäuser Verlag, Basel.

Wiepkema, P. R., 1983. On the significance of ethological criteria for the assessment of animal welfare. In: D. Smidt (Ed.), Indicators relevant to farm animal welfare, p. 71-79. Martinus Nijhoff, Boston.

This synopsis is based on a doctoral thesis entitled 'Het gedrag van mestvarkens in relatie tot huisvesting', State University, Utrecht, 1985. viii + 204 pp., 16 figs., 31 tables, 182 refs., 6 appendices. Dutch, English summary.

Available as paper copy (order R063P, $f 20$ including postage) or microfiches (order R063M, f 22.50 including postage) at: NARD, clo Pudoc, P.O. Box 4, 6700 AA Wageningen, Netherlands (telex 45015 blhwg). 